\title{
The impact of method of distal ureter management during radical nephroureterectomy on tumour recurrence
}

\author{
Anil Kapoor, MD, FRCSC;, Shawn Dason, MD; ; Christopher B. Allard, MD; Bobby Shayegan, MD, FRCSC;, \\ Louis Lacombe, MD, FRCSC; ${ }^{\dagger}$ Ricardo Rendon, MD, FRCSC,; Niels-Erik Jacobsen, MD, FRCSC,; Adrian Fairey, \\ MD, FRCSC,; Jonathan Izawa, MD, FRCSC,; Peter Black, MD, FRCSC;: Simon Tanguay, MD, FRCSC;,

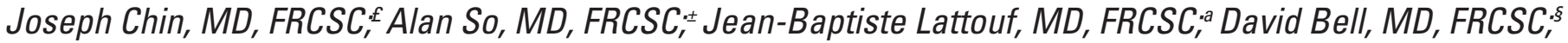 \\ Fred Saad, MD, FRCSC; Darrell Drachenberg, MD, FRCSC;, llias Cagiannos, MD, FRCSC; ${ }^{\circ}$ Yves Fradet, MD, \\ FRCSC,; Abdulaziz Alamri, MD, FRCSC,; Wassim Kassouf, MD, FRCSC ${ }^{*}$
}

*McMaster Universty, Hamilton, ON; †Laval University, Quebec, QC; §Dalhousie University, Halifax, NS; * University of Alberta, Edmonton, AB; \&University of Western Ontario, London, ON; \pm University of British Columbia, Vancouver, BC; \#McGill University, Montreal, QC; anniversity of Montreal, Montreal, QC; bUniversity of Manitoba, Winnipeg, MB; University of Ottawa, Ottawa, ON; 'Kking Khalid University, Abha, Saudi Arabia

Cite as: Can Urol Assoc J 2014;8(11-12):e845-52. http://dx.doi.org/10.5489/cuaj.1985 Published online November 24, 2014.

\section{Abstract}

Introduction: Radical nephroureterectomy for upper tract urothelial carcinoma (UTUC) must include some form of distal ureter management to avoid high rates of tumour recurrence. It is uncertain which distal ureter management technique has the best oncologic outcomes. To determine which distal ureter management technique resulted in the lowest tumour recurrence rate, we analyzed a multiinstitutional Canadian radical nephroureterectomy database.

Methods: We retrospectively analyzed patients who underwent radical nephroureterectomy with distal ureter management for UTUC between January 1990 and June 2010 at 10 Canadian tertiary hospitals. Distal ureter management approaches were divided into 3 categories: (1) extravesical tenting for ureteric excision without cystotomy (EXTRAVESICAL); (2) open cystotomy with intravesical bladder cuff excision (INTRAVESICAL); and (3) extravesical excision with endoscopic management of ureteric orifice (ENDOSCOPIC). Data available for each patient included demographic details, distal ureter management approach, pathology and operative details, as well as the presence and location of local or distant recurrence. Clinical outcomes included overall recurrence-free survival and intravesical recurrence-free survival. Survival analysis was performed with the Kaplan-Meier method. Multivariable Cox regression analysis was also performed.

Results: A total of 820 patients underwent radical nephroureterectomy with a specified distal ureter management approach at 10 Canadian academic institutions. The mean patient age was 69.6 years and the median follow-up was 24.6 months. Of the 820 patients, 406 (49.5\%) underwent INTRAVESICAL, 316 $(38.5 \%)$ underwent EXTRAVESICAL, and 98 (11.9\%) underwent ENDOSOPIC distal ureter management. Groups differed signifi- cantly in their proportion of females, proportion of laparoscopic cases, presence of carcinoma in situ and pathological tumour stage $(p<0.05)$. Recurrence-free survival at 5 years was $46.3 \%, 35.6 \%$, and $30.1 \%$ for INTRAVESICAL, EXTRAVESICAL and ENDOSCOPIC, respectively $(p<0.05)$. Multivariable Cox regression analysis confirmed that INTRAVESICAL resulted in a lower hazard of recurrence compared to EXTRAVESICAL and ENDOSCOPIC. When looking only at intravesical recurrence-free survival (iRFS), a similar trend held up with INTRAVESICAL having the highest iRFS, followed by ENDOSCOPIC and then EXTRAVESICAL management $(p<0.05)$. At last follow-up, $406(49.5 \%)$ patients were alive and free of disease.

Conclusion: Open intravesical excision of the distal ureter (INTRAVESICAL) during radical nephroureterectomy was associated with improved overall and intravesical recurrence-free survival compared with extravesical and endoscopic approaches. These findings suggest that INTRAVESICAL should be considered the gold standard oncologic approach to distal ureter management during radical nephroureterectomy. Limitations of this study include its retrospective design, heterogeneous cohort, and limited follow-up.

\section{Introduction}

Upper urinary tract urothelial carcinoma (UTUC) is a neoplasm arising from the urothelial cells of the renal calyces, renal pelvis, or ureter. ${ }^{1}$ UTUC is a rare disease, with an estimated annual incidence of 1 to 2 cases per 100000 inhabitants in Western countries. ${ }^{2}$ It accounts for $5 \%$ to $10 \%$ of urothelial carcinomas. ${ }^{3-5}$

Radical nephroureterectomy with bladder cuff excision is the gold standard for the treatment of non-metastatic UTUC. ${ }^{2,6}$ In one multi-institutional series, radical nephro- 
ureterectomy for pT1, pT2, pT3 and pT4 disease resulted in a 5-year cancer-specific survival of $91,75,54$ and $12 \%$, respectively. ${ }^{5}$ The importance of appropriate distal ureter management is demonstrated in classic series where the bladder cuff and distal ureter were not removed during radical nephroureterectomy, resulting in recurrence rates of 33\% to $75 \%$ in the ureteric remnant. ${ }^{7-12}$ This likely occurs due to either antegrade seeding of the ureteric stump or panurothelial susceptibility within the entire upper urinary tract. ${ }^{13}$ These high recurrence rates in the distal ureteric stump mirror the rates of metachronous intravesical recurrence after UTUC - presumably by similar mechanisms. ${ }^{1}$

The oncologic principles of distal ureter management include the excision of the entire intramural ureter and ureteric orifice with a surrounding bladder cuff. ${ }^{14}$ This goal may be accomplished by several techniques. The intravesical technique involves a cystotomy with an intravesical excision of the ureteric orifice and intravesical ureter. This technique allows for removal of the entire distal ureter, including the ureteric orifice and surrounding bladder cuff but necessitates the morbidity of a cystotomy. The extravesical technique involves dissecting the distal ureter extravesically, tenting it away from the bladder and contralateral orifice, then excising the distal ureter and bladder cuff. The extravesical technique avoids a cystotomy, but risks an incomplete removal of the distal ureter or damage to the contralateral distal ureter. Endoscopic management of the distal ureter involves some cystoscopic confirmation that the ureteric orifice has been removed with the remainder of the ureter removed extravesically, en-bloc with the specimen. Endoscopic techniques may involve resecting the ureteric orifice down to perivesical fat or transurethrally incising around the ureteric orifice and occluding the free orifice with an Endoloop (Ethicon, Cincinnati, $\mathrm{OH}$ ).

The most appropriate technique for distal ureter management during radical nephroureterectomy is not wellestablished. In efforts to expand this literature, we present an analysis of these distal ureter management techniques based on a separate multi-institutional Canadian radical nephroureterectomy collaboration.

\section{Methods}

Patients who underwent radical nephroureterectomy with distal ureter management for UTUC between January 1990 and June 2010 at 10 Canadian tertiary hospitals were retrospectively analyzed in a pooled database. Institutional review board approval for this study was obtained.

In this series, selection criteria for open or laparoscopic approach, distal ureter management method, extent of lymphadenectomy and receipt of perioperative chemotherapy were not defined a priori. Radical nephroureterec- tomy was performed en bloc with distal ureter management according to oncologic principles. Distal ureter management approaches were categorized as follows: (1) extravesical ureter (EXTRAVESICAL); (2) open intravesical (INTRAVESICAL); and (3) endoscopic (ENDOSCOPIC).

The EXTRAVESICAL approach involved extravesical dissection of the intramural ureter with tenting of the dissected ureter away from the bladder. The distal ureter was excised in the EXTRAVESICAL technique without opening the bladder at another location. The INTRAVESICAL method was performed after radical nephroureterectomy via a Gibson or Pfannenstiel incision and included cystotomy with intravesical excision of a bladder cuff around the intramural ureter and ureteric orifice. The bladder was then closed with absorbable sutures. The ENDOSCOPIC technique was performed prior to nephrouretectomy and consisted of endoscopic incision of a cuff of bladder surrounding the ureteric orifice using a Collings knife; a single needlescopically (5 mm) applied transvesical endoloop was used to occlude the distal ureter and prevent distal seeding. The distal ureter and bladder cuff were then removed extravesically, en bloc with the nephroureterectomy specimen.

Pathologic assessment was performed locally at each tertiary care institution and involved specialized local pathologic review for equivocal cases. Staging was performed according to the 2002 American Joint Committee on Cancer Tumor Node and Metastases staging system for UTUC. ${ }^{15}$ Grading was performed according to the 1998 World Health Organization/International Society of Urologic Pathology consensus. ${ }^{16}$

Follow-up included history, physical examination, basic bloodwork, urinalysis and cytology, chest imaging, cystoscopy and computed tomography urograms. These were performed at intervals of 3 to 6 months initially and then yearly after the initial 2 to 3 years. Additional imaging was obtained when clinically indicated.

Data collected included patient age, distal ureter management approach, tumour location, laparoscopic or open approach, PT stage, grade, presence of concomitant carcinoma in situ, surgical margin status, receipt of perioperative chemotherapy, multifocality, tumour architecture, lymphovascular invasion, nodal status, and location of local or distant recurrence.

Clinical outcomes available included overall recurrencefree survival (RFS) and intravesical recurrence-free survival (iRFS). Overall recurrent disease included recurrences within the bladder, as well as contralateral recurrences, ureteric stump recurrences and distant metastatic disease arising during follow-up. Intravesical recurrences included recurrences within the bladder only.

Survival analysis was performed to determine the relationship between distal ureter management and clinical out- 
comes by Kaplan-Meier method and differences in survival evaluated by the log-rank test. Cox proportional regression analysis was used to determine hazard ratios with $95 \%$ confidence intervals $(\mathrm{Cl})$ relating distal ureter management method and RFS. Variables with a $p$ value $<0.30$ on univariate analysis, defined a priori, were included in the multivariable Cox analysis. A Chi-squared test or t-test was used to evaluate differences in baseline attributes. For all statistical tests, two-tailed $p$ values less than 0.05 were considered significant. Statistical analyses were performed using the SAS (version 9.2) statistical software package (SAS Institute Inc., Cary, NC).

\section{Results}

Between 1990 and 2010, 820 patients underwent radical nephroureterectomy with a specified distal ureter management at 10 Canadian academic institutions. The mean patient age was 69.6 years and $36.6 \%$ were female. The median follow-up was 24.6 months (Q1: 8.2 months, Q3: 56.9 months).

At last follow-up, 406 (49.5\%) patients were alive and free of disease. There were 197 (24.0\% of total) patients known to have died, of which 136 (16.6\% of total) died from disease. A total of 284 (34.6\%) patients had some form of disease recurrence during follow-up, of which 166 (20.2\%) had recurrence within the bladder.

Of the total 820 patients, 406 (49.5\%) patients underwent INTRAVESICAL, 316 (38.5\%) underwent EXTRAVESICAL, and $98(11.9 \%)$ underwent ENDOSOPIC management of the distal ureter during radical nephroureterectomy. We noted patient and clinicopathologic details stratified by distal ureter management technique (Table 1). Groups differed significantly in their proportion of females, proportion of laparoscopic cases, presence of carcinoma in situ and pathological tumour stage $(p<0.05)$.

The total number of recurrences in the INTRAVESICAL, ENDOSCOPIC and EXTRAVESICAL groups were 134, 38, and 112 respectively. RFS for INTRAVESICAL, ENDOSCOPIC, and EXTRAVESICAL at 2 years were $61.6 \%, 55.7 \%$, and $49.6 \%$, respectively $(p<0.05)$. At 5 years the RFS was $46.3 \%$, $35.6 \%$, and $30.1 \%$ for INTRAVESICAL, EXTRAVESICAL and ENDOSCOPIC, respectively $(p<0.05)$. Accordingly, INTRAVESICAL significantly improved RFS compared to EXTRAVESICAL $(p<0.0001)$ and ENDOSCOPIC $(p=0.0006)$ (Fig. 1). ENDOSCOPIC also significantly improved RFS compared to EXTRAVESICAL $(p=0.0166)$, but was inferior to INTRAVESICAL $(p=0.0006)$ (Fig. 1$)$.

In multivariable Cox regression analysis, ENDOSCOPIC was associated with worse RFS (hazard ratio [HR] 1.488,

\begin{tabular}{|c|c|c|c|c|c|c|}
\hline \multirow[t]{2}{*}{ Attribute } & & \multicolumn{4}{|c|}{ Distal ureter management } & \multirow[t]{2}{*}{$p$ value } \\
\hline & & $\begin{array}{l}\text { EXTRAVESICAL } \\
(n=316)\end{array}$ & $\begin{array}{l}\text { INTRAVESICAL } \\
(\mathrm{n}=406)\end{array}$ & $\begin{array}{l}\text { ENDO } \\
(\mathrm{n}=98)\end{array}$ & $\begin{array}{c}\text { All } \\
(n=820)\end{array}$ & \\
\hline \multicolumn{2}{|l|}{ Mean age (SD), years } & $69.9(11.3)$ & $69.2(10.5)$ & $70.0(11.0)$ & $69.6(10.9)$ & 0.96 \\
\hline \multicolumn{2}{|l|}{$\%$ Female } & $42.1 \%$ & $32.0 \%$ & $38.1 \%$ & $36.6 \%$ & 0.02 \\
\hline \multicolumn{2}{|l|}{ Laparoscopic (\%), n } & $150(47.5 \%)$ & $205(50.5 \%)$ & $83(84.7 \%)$ & $438(53.4 \%)$ & $<0.01$ \\
\hline \multicolumn{2}{|c|}{ Perioperative chemotherapy (\%), $\mathrm{n}$} & $41(13.0 \%)$ & $43(10.6 \%)$ & $7(7.1 \%)$ & $91(11.1 \%)$ & 0.23 \\
\hline \multirow[t]{3}{*}{ Tumour location (\%), $\mathrm{n}$} & Renal pelvis & $170(53.8 \%)$ & $205(50.5 \%)$ & $57(58.2 \%)$ & $432(52.7 \%)$ & 0.54 \\
\hline & Ureter & $69(21.8 \%)$ & $107(26.4 \%)$ & $22(22.4 \%)$ & $198(24.1 \%)$ & \\
\hline & Renal pelvis and ureter & $69(21.8 \%)$ & $89(21.9 \%)$ & $18(18.4 \%)$ & $176(21.5 \%)$ & \\
\hline \multicolumn{2}{|c|}{ Mixed or non-UC histology (\%), n } & $11(3.5 \%)$ & $15(3.7 \%)$ & $6(6.1 \%)$ & $32(3.9 \%)$ & 0.47 \\
\hline \multicolumn{2}{|l|}{ High grade (\%), n } & $206(65.2 \%)$ & $261(64.3 \%)$ & $58(59.2 \%)$ & $525(64.0 \%)$ & 0.64 \\
\hline \multicolumn{2}{|l|}{ CIS (\%), n } & $76(24.1 \%)$ & $105(25.9 \%)$ & $12(12.2 \%)$ & $193(23.5 \%)$ & 0.02 \\
\hline \multicolumn{2}{|l|}{ PSM (\%), n } & $32(10.1 \%)$ & $39(9.6 \%)$ & $10(10.2 \%)$ & $81(9.9 \%)$ & 0.95 \\
\hline \multicolumn{2}{|l|}{ Multifocality (\%), n } & $82(25.9 \%)$ & $100(24.6 \%)$ & $30(30.6 \%)$ & $212(25.9 \%)$ & 0.52 \\
\hline \multicolumn{2}{|c|}{ Papillary architecture (\%), n } & $254(80.4 \%)$ & $350(86.2 \%)$ & $89(90.8 \%)$ & $693(84.5 \%)$ & 0.40 \\
\hline \multicolumn{2}{|l|}{ LVI (\%), n } & $212(67.1 \%)$ & $301(74.1 \%)$ & $61(62.2 \%)$ & $574(70.0 \%)$ & 0.54 \\
\hline \multirow[t]{4}{*}{ pT stage } & $<2$ & $127(40.2 \%)$ & $202(49.8)$ & $47(50.0 \%)$ & $376(45.9 \%)$ & 0.02 \\
\hline & 2 & $51(16.1 \%)$ & $57(14.0 \%)$ & $17(17.3 \%)$ & $126(15.4 \%)$ & \\
\hline & 3 & $69(21.8 \%)$ & $89(21.9 \%)$ & $23(23.5 \%)$ & $181(22.1 \%)$ & \\
\hline & 4 & $25(7.9 \%)$ & $11(27.1 \%)$ & $4(4.1 \%)$ & $40(4.9 \%)$ & \\
\hline \multirow[t]{3}{*}{ Nodal metastases } & Absent & 59 (18.7\%) & $87(21.4 \%)$ & $22(22.4 \%)$ & $168(20.5 \%)$ & 0.45 \\
\hline & Present & $25(7.9 \%)$ & $26(6.40 \%)$ & $3(3.1 \%)$ & $54(6.6 \%)$ & \\
\hline & Unknown & $232(73.4 \%)$ & $293(72.2 \%)$ & $73(74.5 \%)$ & $598(72.9 \%)$ & \\
\hline
\end{tabular}

Differences between groups are evaluated with the student's t-test or chi-squared test with a two-tailed p value less than 0.05 defining significance. SD: standard deviation; EXTRAVESICAL: extravesical ureter; INTRAVESICAL: open intravesical; ENDO: extravesical and endoscopic intravesical; UC: urothelial carcinoma; CIS: carcinoma in situ; PSM: positive surgical margin; LVI: lymphovascular invasion; pT: pathological tumour. 


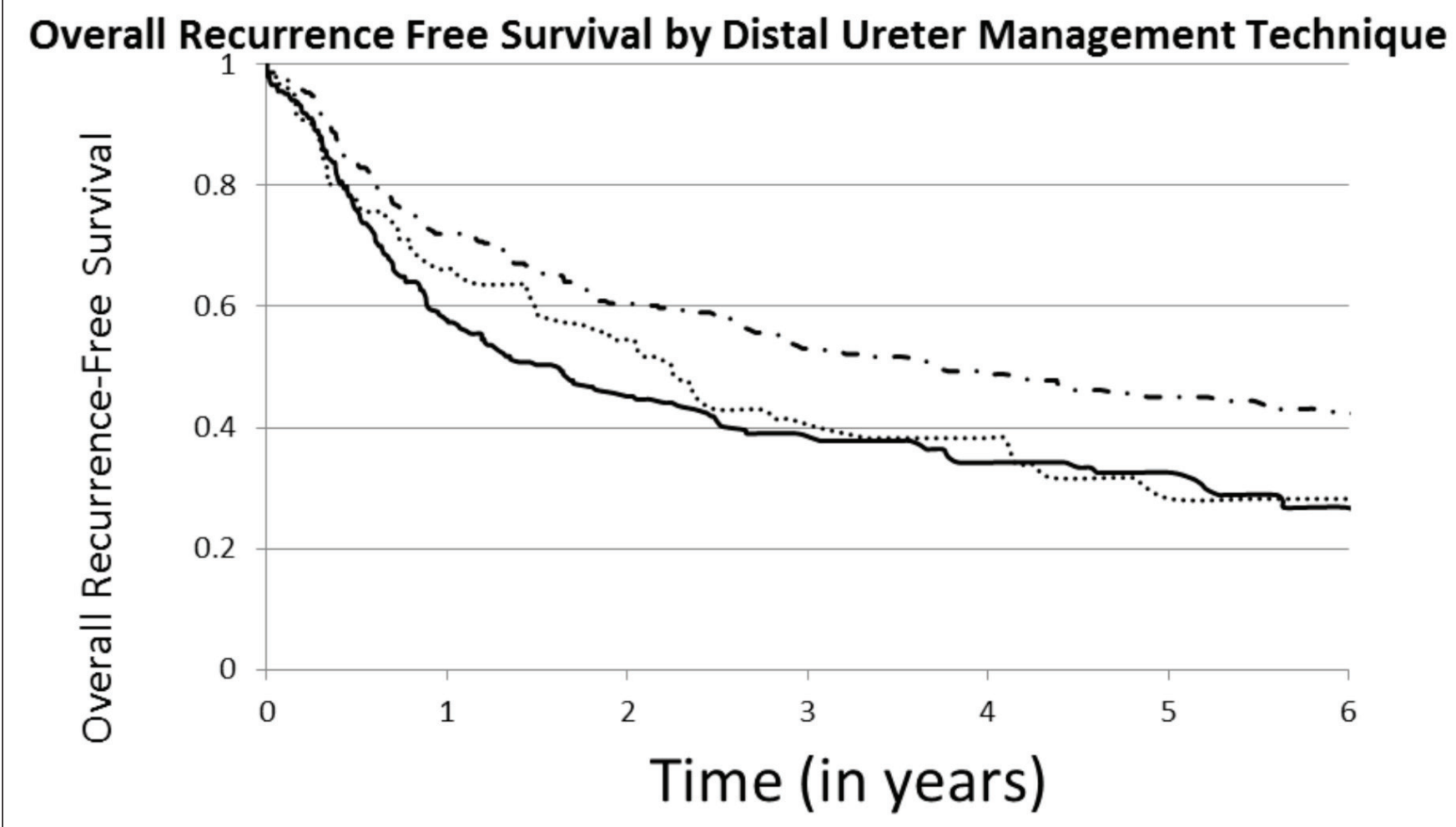

Fig. 1. Recurrence-free survival of patients undergoing radical nephroureterectomy over time, stratified by distal ureter management method. Survival analysis is performed with the Kaplan-Meier method using a log-rank test to evaluate for significant differences. P values less than 0.05 are regarded as significant. EXTRAVESICAL: extravesical excision of distal ureter; INTRAVESICAL: cystotomy with open intravesical excision of ureteric orifice and distal ureter; ENDOSCOPIC: extravesical technique with endoscopic method to ensure adequate removal of distal ureter and ureteric orifice; RFS: recurrence-free survival; SE: standard error; long dash line: INTRAVESICAL; dotted line: ENDOSCOPIC; solid line: EXTRAVESICAL.

95\% Cl 1.014-2.185, $p=0.0424)$ relative to INTRAVESICAL (Table 2). INTRAVESICAL was also associated with superior RFS relative to EXTRAVESICAL (HR $0.628,95 \% \mathrm{Cl} 0.491$ $0.801, p=0.0002)$. On multivariable analysis, RFS did not differ between EXTRAVESICAL and ENDOSCOPIC (HR 0.916 95\% Cl 0.633-1.327) (Table 2).

Other predictors of worsened RFS (HR $>1, p<0.05)$ on multivariable analysis included ureteric and renal tumours, positive surgical margins, receipt of perioperative chemotherapy, and nodal status (Table 2). There was a trend towards worsened RFS with lymphovascular invasion ( $p=0.0591$, HR $1.41295 \% \mathrm{Cl}, 0.987-2.021)$ and tumour multifocality $(p=0.0889, \mathrm{HR} 1.331,95 \% \mathrm{Cl} 0.958-1.849)$.

The total number of bladder recurrences for INTRAVESICAL, ENDOSCOPIC and EXTRAVESICAL was 66, 23 and 77, respectively. When looking only at iRFS, a similar trend held up with INTRAVESICAL having the highest iRFS, followed by ENDOSCOPIC and then EXTRAVESICAL management (Fig. 2). Neither positive margin status nor the distribution of sites of recurrences differed significantly between distal ureter management groups (Table 1, Table 2).

\section{Discussion}

In this study, we have found that an open intravesical approach to distal ureter management (INTRAVESICAL) was associated with an improved RFS and iRFS compared to both extravesical (EXTRAVESICAL) and endoscopic (ENDOSCOPIC) approaches. We postulate that incomplete distal ureteric resections within the EXTRAVESICAL group account for our finding of poorer RFS compared to INTRAVESICAL. It is easy to misperceive the end of the distal ureter and perform an oncologically suboptimal bladder cuff excision, particularly in patients where exposure is difficult (e.g., an obese patient) and the excision is limited due to concerns about excising the contralateral ureteric orifice. Postoperative surveillance guidelines ${ }^{17}$ recommend a surveillance cystoscopy at 3 months after radical nephroureterectomy, and an incomplete distal ureteric resection usually manifests as a visible ureteric orifice at the time of cystoscopy. If the distal ureter is not appropriately removed, recurrence rates can be $33 \%$ to $75 \%$ in the ureteric remnant even in the absence of positive surgical margins..$^{7-12}$ On the other hand, worsened clinical outcomes in the 


\begin{tabular}{|c|c|c|c|c|c|}
\hline \multirow{2}{*}{$\begin{array}{l}\text { Variable } \\
\text { DUM Method }\end{array}$} & \multirow[b]{2}{*}{$\begin{array}{l}\text { INTRAVESICAL vs. } \\
\text { EXTRAVESICAL }\end{array}$} & \multirow{2}{*}{$\begin{array}{c}\boldsymbol{p} \text { value } \\
0.0002\end{array}$} & \multirow{2}{*}{$\begin{array}{c}\text { Multivariable HR } \\
0.628\end{array}$} & \multicolumn{2}{|c|}{ 95\% HR confidence limits } \\
\hline & & & & 0.492 & 0.801 \\
\hline & ENDO vs. EXTRAVESICAL & 0.6440 & 0.916 & 0.633 & 1.327 \\
\hline & ENDO vs. EXTRAVESICAL & 0.0424 & 1.488 & 1.014 & 2.185 \\
\hline Age & & 0.0003 & 1.022 & 1.010 & 1.034 \\
\hline \multirow[t]{2}{*}{ Tumour location } & Ureter vs. renal & 0.9404 & 0.989 & 0.732 & 1.336 \\
\hline & $\begin{array}{l}\text { Ureter and renal vs. renal } \\
\text { only }\end{array}$ & 0.0001 & 1.718 & 1.301 & 2.267 \\
\hline \multicolumn{2}{|c|}{ Laparoscopic vs. open } & 0.1427 & 1.200 & 0.940 & 1.532 \\
\hline \multirow[t]{3}{*}{ pT Stage } & pT2 vs. pT1 & 0.5245 & 1.111 & 0.803 & 1.536 \\
\hline & pT3 vs. pT1 & 0.2257 & 1.199 & 0.894 & 1.607 \\
\hline & pT4 vs. pT1 & 0.4469 & 1.247 & 0.706 & 2.200 \\
\hline \multicolumn{2}{|l|}{ High grade } & 0.1198 & 1.234 & 0.947 & 1.607 \\
\hline \multicolumn{2}{|l|}{ Concurrent $\mathrm{CIS}$} & 0.5939 & 1.079 & 0.817 & 1.424 \\
\hline \multicolumn{2}{|l|}{ PSMs } & 0.0210 & 1.499 & 1.063 & 2.114 \\
\hline \multicolumn{2}{|c|}{ Perioperative chemotherapy } & 0.0003 & 1.897 & 1.338 & 2.689 \\
\hline \multicolumn{2}{|l|}{ Multifocal tumour } & 0.0889 & 1.331 & 0.958 & 1.849 \\
\hline \multicolumn{2}{|c|}{ Sessile architecture } & 0.8866 & 0.958 & 0.535 & 1.718 \\
\hline \multicolumn{2}{|l|}{ LVI } & 0.0591 & 1.412 & 0.987 & 2.021 \\
\hline \multirow[t]{2}{*}{ Nodal status } & No vs. Nx & 0.9322 & 1.012 & 0.767 & 1.336 \\
\hline & N1 vs. Nx & 0.0004 & 2.222 & 1.428 & 3.456 \\
\hline
\end{tabular}

Hazard ratios were determined with a multivariable Cox regression analysis and reported with their $95 \%$ confidence interval and a p value less than 0.05 regarded as significant. HR: hazard ratio; ENDO: extravesical and endoscopic intravesical; DUM: distal ureter management, pT: pathological tumour; CIS: carcinoma in situ; LVI: lymphovascular invasion; PSM: positive surgical margin; EXTRAVESICAL: extravesical ureter; INTRAVESICAL: open intravesical.

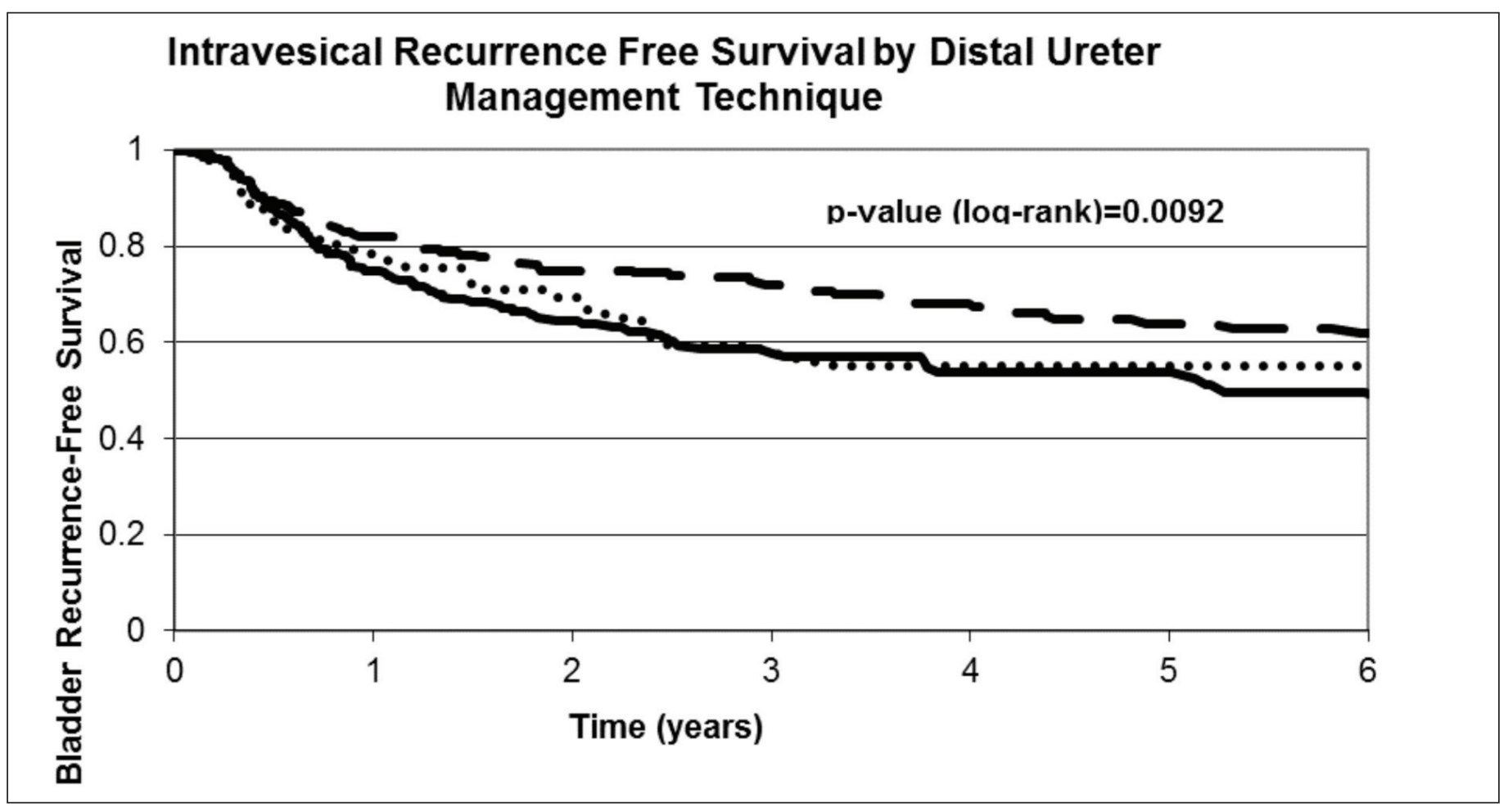

Fig. 2. Intravesical recurrence-free survival (iRFS) of patients undergoing radical nephroureterectomy over time, stratified by distal ureter management method. Survival analysis is performed with the Kaplan-Meier method using a log-rank test to evaluate for significant differences. P values less than 0.05 are regarded as significant. EXTRAVESICAL: extravesical ureter; INTRAVESICAL: extravesical and open intravesical; ENDOSCOPIC: extravesical and endoscopic intravesical; long dash line: INTRAVESICAL; dotted line: ENDOSCOPIC; solid line: EXTRAVESICAL. 
Kapoor et al.

ENDOSCOPIC group might relate to inadequate ureteral occlusion during the procedure or periureteric or perivesical seeding secondary to extravasation.

In efforts to control for confounding variables in predicting recurrence, we have performed multivariable analysis with known clinicopathologic prognosticators. Overall RFS has shown a similar trend of being highest with an INTRAVESICAL technique, found to be superior to ENDOSCOPIC and EXTRAVESICAL groups. ENDOSCOPIC and EXTRAVESICAL did not differ significantly on multivariable analysis. We have not specifically reported multivariable analysis for iRFS as this data are currently under a publication embargo and due to be reported on separately by other members of our collaboration examining another hypothesis. Nonetheless, multivariable analysis for iRFS is consistent with the univariable analysis — with a statistically higher Cox regression hazard ratio of intravesical RFS seen after radical nephroureterectomy with EXTRAVESICAL and ENDOSCOPIC techniques compared to INTRAVESICAL ${ }^{18}$ (oral communication with Dr. J. Mauermann and Dr. W. Kassouf).

A number of prior studies have been published on this topic. The largest of these studies, published by Xylinas and colleagues, ${ }^{19}$ is a multi-institutiona I study of 2681 patients with a median follow-up of 57.5 months. These authors had 1822 patients in their INTRAVESICAL group, 785 in their EXTRAVESICAL group and 85 in their ENDOSCOPIC group. Their techniques were similar in terms of INTRAVESICAL and EXTRAVESICAL, but they describe coagulating the ureteric orifice to prevent distal seeding during radical nephroureterectomy rather than a needlescopically applied Endoloop as generally used in our study. These authors did not find a difference in overall survival, disease-specific survival or RFS when their definition of recurrences excluded intravesical recurrences. When looking at intravesical recurrences, the iRFS for INTRAVESICAL, EXTRAVESICAL and ENDOSCOPIC, respectively, was $69 \%, 69 \%$ and $61 \%$ at 2 years then $58 \%, 51 \%$ and $42 \%$ at 5 years. This showed a statistically significant worse iRFS for ENDOSCOPIC relative to INTRAVESICAL and EXTRAVESICAL. Although EXTRAVESICAL had a lower iRFS than INTRAVESICAL, this result was not statistically significant. Multivariable Cox regression of predictors of intravesical recurrence also demonstrated that ENDOSCOPIC and EXTRAVESICAL both had higher hazards of intravesical recurrence, although only the former was significant. A subsequent study from this collaboration incorporated endoscopic management of the distal ureter as a predictor of intravesical recurrence. ${ }^{20}$ In their multi-institutional series of 773 patients that had overlapping data with Xylinas and colleauges, ${ }^{19}$ Walton and colleagues ${ }^{21}$ have also found endoscopic management to result in higher risks of tumour recurrence and cancer death on multivariable analysis. Ultimately, this large series generally corroborate our findings that a cystotomy with intravesical bladder cuff excision is required to ensure that the entire intramural ureter has been resected.

$\mathrm{Li}$ and colleagues ${ }^{22}$ have reported on 301 patients treated with ENDOSCOPIC $(n=91)$, INTRAVESICAL $(n=81)$, and EXTRAVESICAL $(n=129)$. There were no differences in baseline characteristics between groups and the groups did not differ significantly in rates of bladder recurrence, local retroperitoneal recurrence, contralateral recurrence or distant metastasis. Additionally, there were no differences in RFS and cancer-specific survival between groups. Walton and colleages ${ }^{23}$ have also published a retrospective study comparing ENDOSCOPIC to INTRAVESICAL in 138 patients. These authors report equivalent RFS and disease-specific survival for these techniques. Groups did not significantly differ in recurrences at the resection site or elsewhere in the bladder. Likewise, in their entirely laparoscopic series of 110 patients, Allard and colleagues ${ }^{24}$ found that ENDOSCOPIC, INTRAVESICAL, and EXTRAVESICAL groups had comparable recurrence rates. Numerous smaller non-randomized retrospective studies have been published which do not demonstrate the superiority of any one of these techniques. ${ }^{25,26}$

The lack of outcome differences between techniques other than those found by Xylinas and colleagues ${ }^{19}$ may relate to the fact that other small studies would be underpowered and had limited follow-up. Additionally, large multicentered studies tend to include different techniques, which may reduce the confounding effect of an irreproducible novel technique used in a single centre. Several variations on the endoscopic approach are likely being used, including endoscopic resection of the ureteric orifice, cauterization of orifice followed by excision with a Collings knife, and laparoscopic ligation

Table 3. Sites of local recurrence stratified by method of distal ureter management

\begin{tabular}{|c|c|c|c|c|c|}
\hline \multirow[t]{2}{*}{ Site of recurrence } & \multicolumn{4}{|c|}{ Distal ureter management } & \multirow[b]{2}{*}{$p$ value } \\
\hline & $\begin{array}{l}\text { EXTRAVESICAL } \\
\quad(n=316)\end{array}$ & $\begin{array}{l}\text { INTRAVESICAL } \\
(\mathrm{n}=406)\end{array}$ & ENDO $(n=98)$ & Total $(n=820)$ & \\
\hline Bladder & $66(20.9 \%)$ & 77 (19.9\%) & $23(23.5 \%)$ & $166(20.2 \%)$ & 0.57 \\
\hline Ureteral stump & $1(0.00 \%)$ & $4(0.01 \%)$ & $0(0 \%)$ & $5(0.01 \%)$ & 0.37 \\
\hline Contralateral ureteric & $4(0.01 \%)$ & $4(0.01 \%)$ & $0(0 \%)$ & $8(0.01 \%)$ & 0.54 \\
\hline
\end{tabular}

EXTRAVESICAL: extravesical ureter; INTRAVESICAL: open intravesical; ENDO: extravesical and endoscopic intravesical. 
of the orifice with an Endoloop followed by Collings knife excision. This is relevant because newer modifications in ENDOSCOPIC technique may allow for decreased tumour recurrence. ${ }^{3,5}$ The precise method of ENDOSCOPIC used by many surgeons in this study was not analyzed. The possibility that individual variations on endoscopic management approaches may correlate with improved outcomes should be examined in future prospective studies.

Large variations in the rates and technical details of lymphadenectomy have been described in the literature ${ }^{27,28}$ and accordingly lymphadenectomy was not uniformly performed in this multi-institutional series $(\mathrm{Nx}=72.9 \%)$. Nodal metastases can serve as an independent predictor of recurrence and mortality ${ }^{5}$ and it is unknown if the groups differed in their nodal status without lymphadenectomy. It is also not established whether lymphadenectomy itself may improve outcomes. ${ }^{27}$

The European Association of Urology UTUC guidelines suggest that location of UTUC and multifocality serve as predictors of poor prognosis. Ureteric tumours and multifocal tumours are thought to have worse outcomes than renal pelvic tumours or unifocal tumours. ${ }^{14}$ Studies have been mixed on whether ureteric tumour location serves as an independent predictor of worsened prognosis. ${ }^{29-33}$ Multifocality has been more supported as an independent marker of poor prognosis. ${ }^{32-34}$ In this study, ureteric tumour location was not found to result in worsened RFS on multivariable analysis, although ureteric and renal pelvic tumours had a worsened RFS and there was a trend to worsened RFS with multifocal tumours on multivariable analysis. Because the distribution of tumour location and percentage of patients with multifocality did not differ significantly between groups, our assumption is that whatever selection biases are incurred by these factors are dispersed similarly among groups.

This study was also conducted before the publication of high quality evidence surrounding the use of postoperative intravesical chemotherapy to prevent intravesical recurrences. ${ }^{35-37}$ It is unknown how the use of postoperative intravesical chemotherapy will affect these results.

This study has a number of limitations that may bias its results. These include its retrospective nature, large time period (1990-2010), lack of centralized pathologic review and heterogeneity in institutional practice patterns. Because this was an observational study, there was no systematic control on which patients received each distal ureter management technique. Additionally, even within distal ureter management groups, subtle technical variations exist that may confound the overall results.

Accordingly, some clinicopathologic parameters differed between groups. INTRAVESICAL had the lowest utilization among female patients and may relate to real or perceived cosmetic concerns about an additional incision. ENDOSCOPIC was more commonly utilized with laparoscopic radical nephroureterectomy compared to EXTRAVESICAL and INTRAVESICAL, a trend likely attributable to minimally invasive surgeons being more likely to employ both techniques. ENDOSCOPIC methods were less likely to be employed in the presence of carcinoma in situ possibly due to concerns of perivesical seeding. Pathologic tumour stage when analyzed as a whole also differed between groups-but we felt that this was an artifact of having low numbers in some $\mathrm{pT}$ stages rather than a real clinically significant difference.

Although INTRAVESICAL may be associated with improved oncologic outcomes, we did not have the data to evaluate the morbidity of INTRAVESICAL. INTRAVESICAL may necessitate an additional incision, added operative time and a more extensive dissection. It is unknown how these requirements affect meaningful outcomes, such as post-procedural complications, cost, and quality of life. A patient's life expectancy, compliance with surveillance for intravesical recurrence, and risk for postoperative complications are thus important considerations in choosing a distal ureter management technique.

Median follow-up for all patients was 24.6 months in this study. Margulis and colleagues have previously reported median times to all-cause mortality and cancer-specific mortality at 24.0 and 18.5 months, respectively, after radical nephroureterectomy. ${ }^{5}$ Due to limited follow-up, overall survival and cancer-specific survival for each technique have not been reported. On the other hand, median time to tumour recurrence has previously been found to be 10.4 months, ${ }^{5}$ which is similar to this study.

\section{Conclusion}

Open intravesical excision of the distal ureter and bladder cuff (INTRAVESICAL) during radical nephroureterectomy for upper urinary tract urothelial carcinoma was associated with improved overall and intravesical recurrence free survival compared with EXTRAVESICAL and ENDOSCOPIC approaches. These findings suggest that INTRAVESICAL should be considered the gold standard approach for distal ureter management during radical nephroureterectomy with respect to preventing tumour recurrence. While an intravesical technique may provide the best oncologic outcomes, a patient's life expectancy, compliance with surveillance for intravesical recurrence, and risk for postoperative complications are also important considerations in choosing a technique.

Competing interests: Dr. Kapoor, Dr. Dason, Dr. Allard, Dr. Shayegan, Dr. Lacombe, Dr. Rendon, Dr. Jacobsen, Dr. Fairey, Dr. Izawa, Dr. Black, Dr. Tanguay, Dr. Chin, Dr. So, Dr. Lattouf, Dr. Bell, Dr. Saad, Dr. Drachenberg, Dr. Cagiannos, Dr. Fradet, Dr. Alamri and Dr. Kassouf all declare no competing financial or personal interests. 
Kapoor et al.

This paper has been peer-reviewed.

\section{References}

1. Wein AL, Kavoussi LR, Campbell MF. Campbell-Walsh Urology. 10th ed. Philadelphia, PA: Elsevier Saunders; 2012.

2. Roupret $M$, Zigeuner R, Palou J, et al. European guidelines for the diagnosis and management of upper urinary tract urothelial cell carcinomas: 2011 update. Eur Urol 2011;59:584-94. http://dx.doi. org/10.1016/j.eururo.2010.12.042

3. Munoz JJ, Ellison LM. Upper tract urothelial neoplasms: Incidence and survival during the last 2 decades. J Urol 2000;164:1523-5. http://dx.doi.org/10.1016/S0022-5347(05)67019-X

4. Hall MC, Womack S, Sagalowsky Al, et al. Prognostic factors, recurrence, and survival in transitional cell carcinoma of the upper urinary tract: A 30-year experience in 252 patients. Urology 1998;52:594-601. http://dx.doi.org/10.1016/S0090-4295(98)00295-7

5. Margulis V, Shariat SF, Matin SF, et al. Outcomes of radical nephroureterectomy: A series from the Upper Tract Urothelial Carcinoma Collaboration. Cancer 2009;115:1224-33. http://dx.doi.org/10.1002/ cncr. 24135

6. Campbell MF, Wein AJ, Kavoussi LR. Campbell-Walsh Urology. 9th ed. Philadelphia, PA: Elsevier Saunders; 2007.

7. McCarron JP, Mills C, Vaughn ED Jr. Tumors of the renal pelvis and ureter: Current concepts and management. Semin Urol 1983;1:75-81.

8. Kakizoe T, Fuijta J, Murase T, et al. Transitional cell carcinoma of the bladder in patients with renal pelvic and ureteral cancer. J Urol 1980;124:17-9.

9. Babaian RJ, Johnson DE. Primary carcinoma of the ureter. J Urol 1980;123:357-9.

10. Bloom NA, Vidone RA, Lytton B. Primary carcinoma of the ureter: A report of 102 new cases. J Urol 1970;103:590-8.

11. Strong DW, Pearse HD. Recurrent urothelial tumors following surgery for transitional cell carcinoma of the upper urinary tract. Cancer 1976;38:2173-83. http://dx.doi.org/10.1002/10970142(197611)38:5<2178::AID-CNCR2820380548>3.0.C0;2-1

12. Strong DW, Pearse HD, Tank ES Jr, et al. The ureteral stump after nephroureterectomy. J Urol 1976;115:654-5.

13. Johnson DE, Babaian RJ. Conservative surgical management for noninvasive distal ureteral carcinoma. Urology 1979;13:365-7. http://dx.doi.org/10.1016/0090-4295(79)90331-5

14. Rouprêt $M$, Babjuk $M$, Compérat $E$, et al. European guidelines on upper tract urothelial carcinomas: 2013 update. Eur Urol 2013;63:1059-71. http://dx.doi.org/10.1016/j.eururo.2013.03.032

15. Greene FL, Page DL, Fleming ID, et al. AJCC Cancer Staging Manual, 6th ed. New York: Springer-Verlag; 2002.

16. Epstein Jl, Amin MB, Reuter VR, et al. The World Health Organization/International Society of Urological Pathology consensus classification of urothelial (transitional cell) neoplasms of the urinary bladder. Bladder Consensus Conference Committee. Am J Surg Pathol 1998;22:1435-48. http://dx.doi. org/10.1097/00000478-199812000-00001

17. Kapoor $A$, Allard $C B$, Black $P$, et al. Canadian guidelines for postoperative surveillance of upper urinary tract urothelial carcinoma. Can Urol Assoc J 2013;7:306-11. http://dx.doi.org/10.5489/cuaj.1578

18. Mavermann J, Fradet $Y$, Kassouf W, et al. 767 Risk factors for bladder cancer recurrence after nephroureterectomy for upper tract urothelial tumors: A multicenter analysis of 742 patients. Eur Urol Suppl 2012;11:e767-ea. http://dx.doi.org/10.1016/S1569-9056(12)60764-7

19. Xylinas $E$, Rink $M$, Cha EK, et al. Impact of distal ureter management on oncologic outcomes following radical nephroureterectomy for upper tract urothelial carcinoma. Eur Urol 2014;65:210-7.

20. Xylinas E, Kluth L, Passoni $\mathrm{N}$, et al. Prediction of intravesical recurrence after radical nephroureterectomy: Development of a clinical decision-making tool. Eur Urol 2014; 65(3):650-8.

21. Walton TJ, Novara G, Matsumoto K, et al. Oncological outcomes after laparoscopic and open radical nephroureterectomy: results from an international cohort. BJU Int 2011;108:406-12. http://dx.doi. org/10.1111/i.1464-410X.2010.09826.x
22. Li WM, Shen JT, Li CC, et al. Oncologic outcomes following three different approaches to the distal ureter and bladder cuff in nephroureterectomy for primary upper urinary tract urothelial carcinoma. Eur Urol 2010;57:963-9. http://dx.doi.org/10.1016/i.eururo.2009.12.032

23. Walton TJ, Sherwood BT, Parkinson RJ, et al. Comparative outcomes following endoscopic ureteral detachment and formal bladder cuff excision in open nephroureterectomy for upper urinary tract transitional cell carcinoma. J Urol 2009;181:532-9. http://dx.doi.org/10.1016/i.juro.2008.10.032

24. Allard CB, Alamri A, Dason $S$, et al. The method of bladder cuff excision during laparoscopic radical nephroureterectomy does not affect oncologic outcomes in upper tract urothelial carcinoma. World J Urol 2013;31:175-81.

25. Phe $V$, Cussenot 0 , Bitker $M 0$, et al. Does the surgical technique for management of the distal ureter influence the outcome after nephroureterectomy? BJU Int 2011;108:130-8. http://dx.doi.org/10.1111/ j.1464-410X.2010.09835.x

26. Macejko AM, Pazona JF, Loeb $S$, et al. Management of distal ureter in laparoscopic nephroureterectomy-a comprehensive review of techniques. Urology 2008;72:974-81. http://dx.doi.org/10.1016/j.urology.2008.04.022

27. Roscigno $M$, Brausi $M$, Heidenreich $A$, et al. Lymphadenectomy at the time of nephroureterectomy for upper tract urothelial cancer. Eur Urol 2011;60:776-83. http://dx.doi.org/10.1016/i.eururo.2011.07.009

28. Weight $\mathrm{CJ}$, Gettman MT. The emerging role of lymphadenectomy in upper tract urothelial carcinoma. Urol Clin North Am 2011;38:429-37. http://dx.doi.org/10.1016/j.ucl.2011.07.012

29. Ouzzane $A$, Colin $P$, Xylinas $E$, et al. Ureteral and multifocal tumours have worse prognosis than renal pelvic tumours in urothelial carcinoma of the upper urinary tract treated by nephroureterectomy. Eur Urol 2011;60:1258-65. http://dx.doi.org/10.1016/i.eururo.2011.05.049

30. Favaretto RL, Shariat SF, Chade DC, et al. The effect of tumor location on prognosis in patients treated with radical nephroureterectomy at Memorial Sloan-Kettering Cancer Center. Eur Urol 2010;58:574-80. http://dx.doi.org/10.1016/i.eururo.2010.07.003

31. Isbarn H, Jeldres C, Shariat SF, et al. Location of the primary tumor is not an independent predictor of cancer specific mortality in patients with upper urinary tract urothelial carcinoma. J Urol 2009;182:217781. http://dx.doi.org/10.1016/i.juro.2009.07.035

32. Yafi FA, Novara G, Shariat SF, et al. Impact of tumour location versus multifocality in patients with upper tract urothelial carcinoma treated with nephroureterectomy and bladder cuff excision: A homogeneous series without perioperative chemotherapy. BJU Int 2012;110:E7-13. http://dx.doi.org/10.1111/i.1464410X.2011.10792.x

33. Williams AK, Kassouf $W$, Chin J, et al. Multifocality rather than tumor location is a prognostic factor in upper tract urothelial carcinoma. Urol Oncol 2013;31:1161-5. http://dx.doi.org/10.1016/i. urolonc.2011.12.004

34. Chromecki TF, Cha EK, Faikovic $\mathrm{H}$, et al. The impact of tumor multifocality on outcomes in patients treated with radical nephroureterectomy. Eur Urol 2012;61:245-53. http://dx.doi.org/10.1016/i. eururo.2011.09.017

35. Ito $\mathrm{A}$, Shintaku $\mathrm{I}$, Satoh $M$, et al. Prospective randomized phase II trial of a single early intravesical instillation of pirarubicin (THP) in the prevention of bladder recurrence after nephroureterectomy for upper urinary tract urothelial carcinoma: The THP Monotherapy Study Group Trial. J Clin Oncol 2013;31:1422-7. http://dx.doi.org/10.1200/JC0.2012.45.2128

36. Sakamoto N, Naito S, Kumazawa J, et al. Prophylactic intravesical instillation of mitomycin C and cytosine arabinoside for prevention of recurrent bladder tumors following surgery for upper urinary tract tumors: A prospective randomized study. Int I Urol 2001;8:212-6.

37. O'Brien T, Ray E, Singh R, et al. Prevention of bladder tumours after nephroureterectomy for primary upper urinary tract urothelial carcinoma: A prospective, multicentre, randomised clinical trial of a single postoperative intravesical dose of mitomycin C (the ODMIT-C Trial). Eur Urol 2011;60:703-10. http:// dx.doi.org/10.1016/i.eururo.2011.05.064

Correspondence: Dr. Anil Kapoor, Department of Surgery - G340, McMaster University, St Joseph's Hospital, 50 Charlton Ave. East, Hamilton 0N L8N 4A6; akapoor@mcmaster.ca 